\title{
Biochemical and Morphological Studies of Rat Submandibular Gland: I. Gentrifugal Fractionation of Granule-Rich Fraction
}

\author{
C. T. HANKS and S. G. CHAKRABARTI*
}

Institute of Dental Research, Departments of Oral Pathology and Oral Biology, School of Dentistry, University of Michigan, Ann Arbor, Michigan 48104, USA

Submandibular glands from male rats were homogenized in $0.34 \mathrm{M}$ sucrose and $0.5 \mathrm{mM}$ ethylenediaminetetraacetic acid in $10 \mathrm{mM}$ HEPES buffer at a $p H$ of 7.4. The extract was centrifuged and fltered through nuclepore filters to prepare a granule-rich fraction. Electron dense zymogen granules constituted approximately $85 \%$ of the particles in this fraction which also contained about a third of the total alkaline esterase activity in the gland.

In addition to protein digestive properties, trypsinlike proteolytic enzymes of rodent submandibular glands (SMGs) have been shown to promote vascular permeability, smooth muscle contraction, increased blood pressure, and growth of a number of embryonic and cultured tissues. ${ }^{1-5}$ Most research in this area has dealt with isolation and purification of soluble proteins from whole gland homogenates. A few investigators have isolated the granule-rich fractions from either rat or mouse SMG homogenates and have shown evidence that the granules are responsible for a major part of the peptidase and other biologic activity of this gland.3,6,7 In addition, the progressive accumulation of alkaline protease activity has been associated with the maturation of rodent SMGs. 8 Presence of this enzyme activity appears to be related to differentiation of the ductal system and to be under the influence of such endocrine factors as testosterone and thyroxin. $8-11$

This investigation was supported, in part, by National Institutes of Health Research Grants No. DE02731 and DE02289 from the National Institute of Dental Research, Bethesda, Md.

Received for publication October $7,1974$.

Accepted for publication March 4, 1975 .

- Present address: Division of Dermatology, Howard University Medical College, Washington, DC.
It is necessary to isolate and purify individual proteins in order to study the relationships between the alkaline esteropeptidases (AEPS), their biologic activities, and the growth and development hormones. Therefore, this article describes, as a first step, the isolation of organelle-rich fractions from rat SMG homogenate by differential centrifugation and determination of the relative amounts of AEP activity in each subcellular fraction.

\section{Materials and Methods}

Preparation of Centrifugal fractions.Adult male rats weighing between 400 and $500 \mathrm{gm}$ each were killed by cervical dislocation and exsanguination through the inferior vena cava. The submandibular glands were immediately removed, dissected free of connective tissue, minced with razor blades, and homogenized, in a glass Potter-Elvehjem mortar $(30 \mathrm{ml})$ with a fitted Teflon pestle turning at maximum speed on a stirring apparatus $^{b}$ for three up-and-down strokes. This was followed by three more up-and-down strokes of a loose, Dounce homogenizera (41 $\mathrm{ml}$ ) fitted with a loose glass pestle. The homogenate was then filtered through four layers of clean cheesecloth to remove fibrous connective tissue and large tissue debris.

The fractionation scheme used is shown in Figure 1. All steps were done at 0 to $4 \mathrm{C}$ on an ice bath. The homogenizing medium consisted of $0.34 M$ sucrose and $0.5 \mathrm{mM}$ ethylenediaminetetraacetic acid (EDTA) in $10 \mathrm{~m} M$ HEPES buffer, with a $\mathrm{pH}$ of 7.4 . The glands were homogenized as a $5 \%$ $(w / v)$ suspension, and the homogenate was

arthur Thomas Co., Philadelphia, Pa.

b Model 134-2, Talboy Engineering Co., Emerson, NJ. 


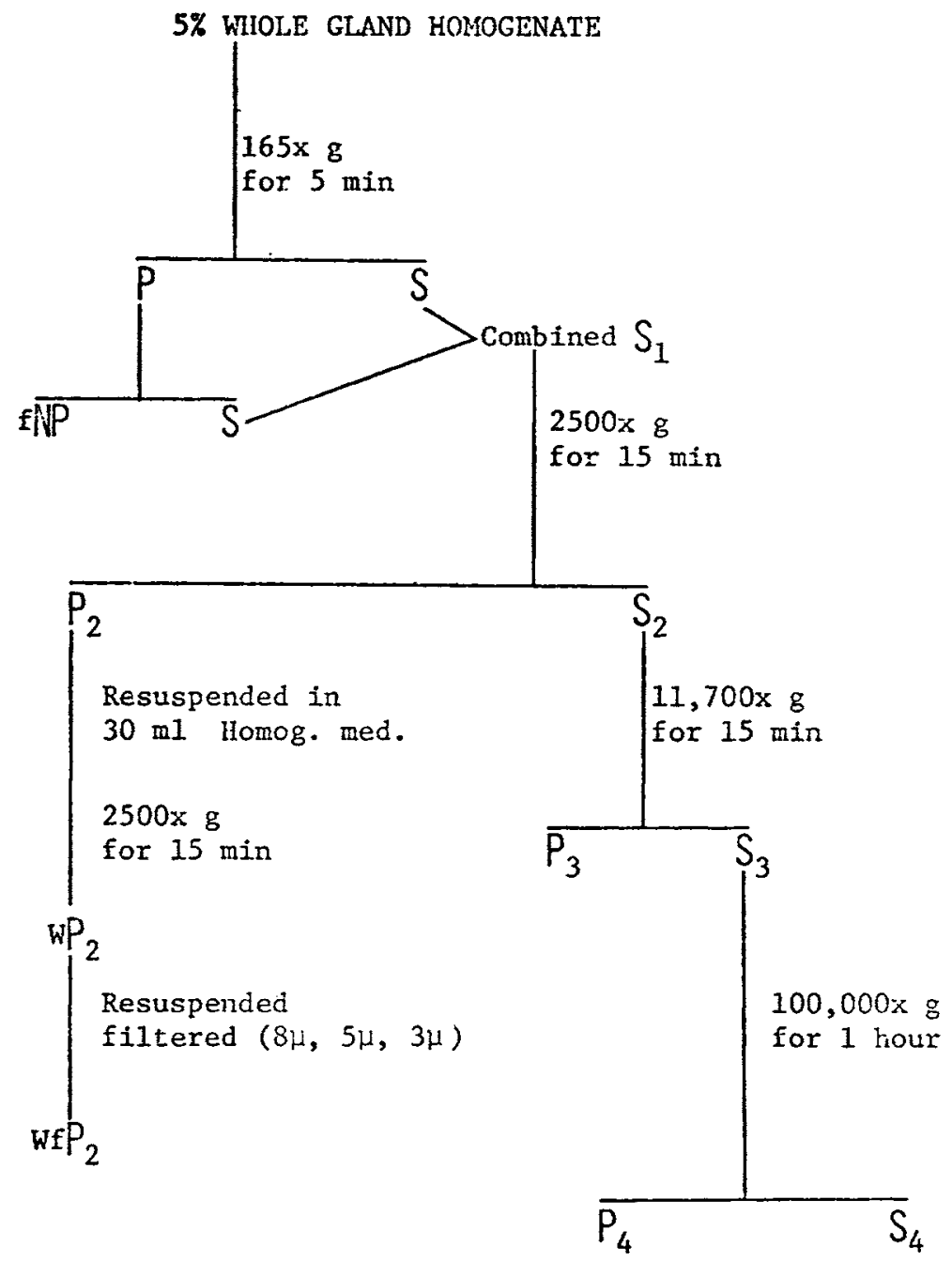

Fig 1.-Centrifugal fractionation and filtration scheme for homogenized rat SMG.

centrifugede for five minutes at $165 \times \mathrm{g}$. The pellet was suspended in a volume of homogenizing medium equal to the supernatant removed and centrifuged again under identical conditions. The combined postnuclear supernatant $\left(S_{1}\right.$, a $2.5 \%$ gland suspension) was centrifuged at $2,500 \times \mathrm{g}$ for 15 minutes to prepare a single, crude, granulerich fraction $\left(\mathbf{P}_{2}\right) . \mathbf{P}_{2}$ was then washed with $30 \mathrm{ml}$ of homogenizing medium and filtered through 8-, 5-, and 3- micrometer $(\mu \mathrm{m})$

\footnotetext{
c Sorvall RC2-B centrifuge.
}

nuclepore filters, ${ }^{d}$ successively, to obtain a purer granule-rich fraction $\left(\mathrm{wfP}_{2}\right)$. Fractions were frozen in liquid nitrogen and stored at $-70 \mathrm{C}$ for subsequent biochemical assays.

The supernatant $\left(S_{2}\right)$ resulting from 2,500 $X g$ centrifugation was then centrifuged at $11,700 \times \mathrm{g}$ for 15 minutes to separate a mitochondria-rich fraction $\left(\mathrm{P}_{3}\right)$ from the post-mitochondrial supernatant $\left(S_{3}\right)$. The $\mathrm{S}_{3}$ fraction, in turn, was centrifuged at

d Arthur H. Thomas Co., Philadelphia, Pa. 
$100,000 \times g$ for one hour in a preparative ultracentrifuge $e^{e}$ using a high-speed rotor for preparation of a microsome-rich pellet $\left(\mathrm{P}_{4}\right)$ and final supernatant $\left(S_{4}\right)$.

BIOCHEMICAL ASSAYS.-Esterase activity was measured using as substrate, $0.5 \mathrm{mM}$ BAEE, $g$ in $0.1 M$ glycine-NaOH buffer $(\mathrm{pH}, 9.2)$ or $0.1 M$ Tris buffer $(\mathrm{pH}, 6.0)$. The esterase activity was determined by the rate of change of absorbance (with time) at a 253-nm wavelength with use of a double-beam recording spectrophotometerh. 12

For measuring peptidase activity, BAPA ${ }^{1}$ was used as a substrate. The incubation mixture consisted of $1 \mathrm{ml}$ of $0.1 M$ glycine$\mathrm{NaOH}$ buffer with a pH of 9.2 (or $0.1 \mathrm{M}$ Tris-HCl buffer with a pH of 8.0$), 0.5 \mathrm{ml}$ of sample solution, and $0.5 \mathrm{ml}$ of $1 \mathrm{mM}$ BAPA (in the same buffer). After incubation at $37 \mathrm{C}$ for the appropriate time (15 to 60 minutes), the reaction was terminated by the addition of (and mixing) $1 \mathrm{ml}$ of $1 \mathrm{M}$ sodium acetate- $\mathrm{HCl}$ buffer, with a $\mathrm{pH}$ of 4.2. The amount of paranitroaniline liberated was determined by measuring the increase in absorbance at $410 \mathrm{~nm}$ with use of a spectrophotometer ${ }^{j}$ against a reagent blank treated similarly (except that $0.5 \mathrm{ml}$ of buffer was used instead of enzyme solution in the blank cuvette). A calibration curve was prepared using paranitroaniline and the same experimental conditions, according to Ekfors, Malmiharju, and Hopsu-Havu. ${ }^{13}$

Acid phosphatase (EC 3.1.3.2) activity in various fractions was determined at $37 \mathrm{C}$ and at a $\mathrm{pH}$ of 6.0 by sodium phenolphthalein hydrolysis according to the method of Huggins and Talalay.14 Succinoxidase activity was determined by measuring the formazan products resulting from electron transfer from several "mitochondrial" enzymes to nitro blue tetrazolium according to the method of Nachlas, Margulis, and Seligman.15 Glucose-6-phosphatase (EC 3.1.3.9) activity was assayed by measuring the amount of inorganic phosphorus released from the substrate after incubation with the fractions according to the method of Fiske and Subbarow. ${ }^{16}$

\footnotetext{
- Spinco model L2-65B, Beckman Instruments, Inc., Fullerton, Calif.

I SW27, Beckman Instruments, Inc, Fullerton, Calif. s $N$-benzoyl- $L$-arginine ethyl ester-hydrochloride.

${ }^{n}$ Bausch and Lomb Spectronic 505, Bausch and Lomb, Rochester, NY.

${ }^{1} N$-benzoyl- $D L$-arginine-p-nitroanilide hydrochloride.

$\checkmark$ Bausch and Lomb Spectronic 70, Bausch and Lomb, Rochester, NY.
}

The method of Lowry et al17 was used to determine protein concentrations. Total enzymatic activity was expressed as the number of micromoles of substrate hydrolyzed per minute per fraction, and specific activity was expressed as the number of micromoles of substrate hydrolyzed per minute per milligram of protein.

LIGHT AND ELECTRON MICROSCOPY.-The content of pelleted material from each step of the fractionation procedure was quickly evaluated by spreading a drop of suspension on a clean glass slide and staining it with $1 \%$ toluidine blue in a $1 \%$ sodium borate solution. In this manner, nuclei, mitochondria, secretory granules, and microsomes could be distinguished at the light microscopic level. Fresh pellets were also suspended in $2.5 \%$ glutaraldehyde in $0.1 \mathrm{M}$ sodium phosphate buffer ( $\mathrm{pH}, 7.2$ ) for a period from two hours to overnight at $4 \mathrm{C}$. After pelleting by centrifugation, the fractions were postfixed in $2 \%$ osmium tetroxide for two hours. Rapid dehydration was done either in an acetone series or an ethyl alcohol-propylene oxide series, and was followed by embedding in epoxy resink. ${ }^{\mathrm{k}}, 18$ Representative blocks from pellets and segments of pellets were sectioned at approximately $0.5 \mu \mathrm{m}$ for light microscopy and at approximately $0.1 \mu \mathrm{m}$ for electron microscopy. Toluidine blue was used for staining the $0.5 \mu \mathrm{m}$ sections on glass slides, whereas uranyl acetate ${ }^{20}$ and lead citrate 21 were used for staining the $0.1-\mu \mathrm{m}$ sections on formvarcoated or uncoated copper grids (200- and 300-mesh). Thin sections were studied with an electron microscope ${ }^{\mathrm{l}}$ at $60 \mathrm{kv}$ accelerating voltage.

To determine the approximate number of different organelles in typical centrifugal fractions, electron micrographs were taken at a magnification of $\times 500$. A glass grid $6 \times 6.5 \mathrm{~cm}$ was then placed over negative images of the fractions and the numbers of each type of organelle were tallied per a $39-\mathrm{cm}^{2}$ area of negative (representing approximately a $150-\mu \mathrm{m}^{2}$ area of unmagnified pellet). Standard error of the mean was calculated for the $P_{2}$ fraction only since the strands and particles of endoplasmic reticulum became so numerous as to be uncountable in fractions $P_{3}$ and $P_{4}$.

Supernatant fractions were handled simi-

L Ladd Research Industries, Inc., Burlington, Vt.

1 Model 9A, Carl Zeiss, Inc., New York, NY. 
larly to pellet fractions except that equal volumes of $5 \%$ buffered glutaraldehyde were added to the supernatant for overnight prefixation before centrifugation. Osmium tetroxide postfixation, dehydration, and embedding were done routinely as just described.

Several $\mathrm{P}_{2}$ fractions were viewed under the scanning electron microscope in an attempt to distinguish between mitochondria and secretory granules and to evaluate the surface characteristics of the secretory granules. These fractions were prepared by spreading the pelleted material on nuclepore filters, fixing them in sodium phosphate buffered $2.5 \%$ glutaraldehyde, and quickly dehydrating them in acetone. The dried filters were then placed on a metal specimen block, coated with a $150 \mathrm{~A}$ gold film, and scanned at a magnification of $\times 3,000$ under a scanning electron microscope $\mathrm{e}^{\mathrm{m}}$ at $15 \mathrm{kv}$.

Histochemistry,-Slices of SMGs and sublingual gland were fixed in acetone and incubated with the trypsin substrates, BAPA and BANA. ${ }^{\mathrm{n}}$ The combinations of methods that gave the best results for the two substrates are described. The tissue was fixed in $100 \%$ acetone at $4 \mathrm{C}$ for 18 to 24 hours, then subjected to a toluene dehydration series from 30 to $100 \%$ at 30 -minute intervals on an ice bath, followed by vacuum em. bedding in paraffin (melting point, $5 \mathrm{C}$ ) . This method proved superior to the following methods of fixation and dehydration:

(I) $4 \%$ Formalin in a $0.1 \quad M$ phosphate buffer followed by ethanol dehydration, (2) $6 \%$ glutaraldehyde in $0.1 M$ phosphate buffer followed by ethanol dehydration, (3) $95 \%$ ethanol followed by xylene dehydration, (4) or freeze-drying in liquid nitrogen after allowing tissue to remain for several hours in $0.88 M$ sucrose, $10 \%$ dimethylsulfoxide (DMSO) or 5 to $20 \%$ polyvinyl alcohol for subsequent cryostat microtomy.

After embedding, the paraffin sections were cut at a $5 \mu \mathrm{m}$ thickness, placed on glass slides, and incubated at various temperatures from 4 to $52 \mathrm{C}$ in coplin jars, according to the method of Hopsu and Glenner. ${ }^{22}$

For the substrate BAPA, the incubating mixture included: $1 \mathrm{ml}$ of $1.1 \mathrm{~m} M$ BAPA and $9 \mathrm{ml}$ of $0.1 \mathrm{M}$ buffer (Tris- $\mathrm{HCl}$ with a

\footnotetext{
m Model JEM P3, Jeolco (USA), Inc., Medford, Mass. ride.

n N-benpoyl- $D L$-arginine-b-naphthylamide hydrochlo-
}

$\mathrm{pH}$ of 8.2; glycine- $\mathrm{NaOH}$ with a $\mathrm{pH}$ of 9.2) . A positive reaction was evident within five minutes in the reaction vessel at room temperature.

For the substrate BANA, a postcoupling reaction was most efficient. The hydrolysis incubation mixture included: $1 \mathrm{ml}$ of 1.1 $\mathrm{m} M$ BANA (solubilized first in $0.1 \mathrm{ml}$ DMSO and then diluted in water) and $9 \mathrm{ml}$ of 0.1 $M$ buffer (Tris- $\mathrm{HCl}$, with a $\mathrm{pH}$ of 8.2 ; glycine- $\mathrm{NaOH}$ with a $\mathrm{pH}$ of 9.2). This incubation reaction was allowed to proceed for 15 minutes at room temperature after which the slides were placed in another coplin jar for coupling. The coupling solution contained 1 $\mathrm{ml}$ of dye stock (3.5 fast Garnet $\mathrm{GBC} / \mathrm{ml}$ distilled water), $1 \mathrm{ml}$ of $10 \%$ Tween 20 , and $8 \mathrm{ml}$ of 0.1 buffer (same buffer as in hydrolysis reaction). The coupling reaction took place within five minutes at room temperature.

\section{Results}

LighT MICRosCopy.-Acetone-fixed sections of normal rat SMG when incubated with BANA and postcoupled with fast Garnet GBC or when incubated with BAPA gave

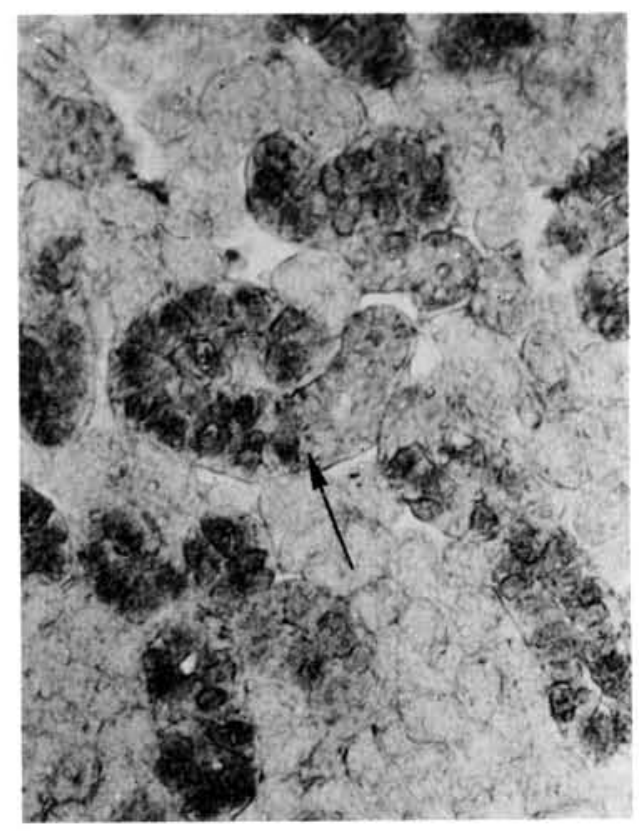

FIG 2.-Photomicrograph of acetone-fixed, paraffin-embedded rat SMG incubated with 0.11 $\mathrm{m} M$ BANA (pH, 9.2) and postcoupled with fast Garnet GBC. Darker staining structure (arrow) represents convoluted tubules $(\mathrm{mag} \times 200)$. 
identical and characteristic reaction patterns (Fig 2). The dark-brown reaction product was, in all instances, localized over the area of the ductal system of the SMG which is consistent with the pattern of the convoluted granular tubules under routine staining conditions (Fig 3). No reaction product was localized over the ductal system area of the sublingual gland in control sections. When pellets derived from steps in the centrifugal fractionation procedure were stained with toluidine blue, the granules were easily distinguishable from background particulate (mitochondria) and stringy material (microsomes) to which they were adherent. When such a pellet was observed in thick sections cut from epoxy resin blocks ${ }^{n}$ prepared for electron microscopy by routine methods, the

n Epon 812, Ernest F. Fullam Inc., Schnectady, NY.

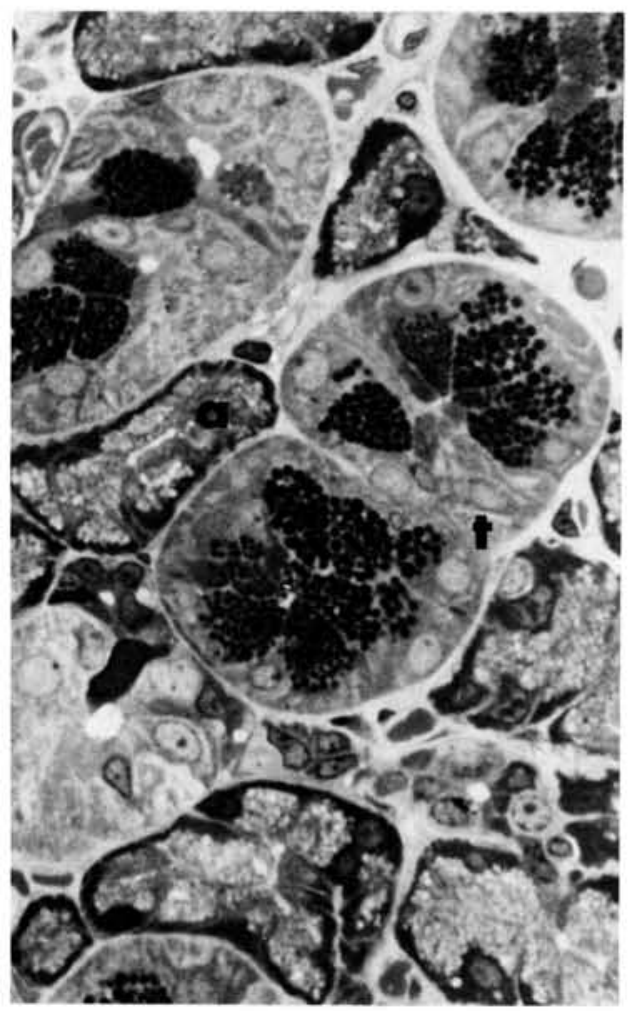

Fig 3.-Photomicrograph of epoxy resin-em. bedded section of adult male SMG shows convoluted tubules ( $t$ ) and acinar structures (a). Cells of convoluted tubules vary as to number of dense granules they contain, as well as size and staining qualities of these granules (mag $\times 650)$.

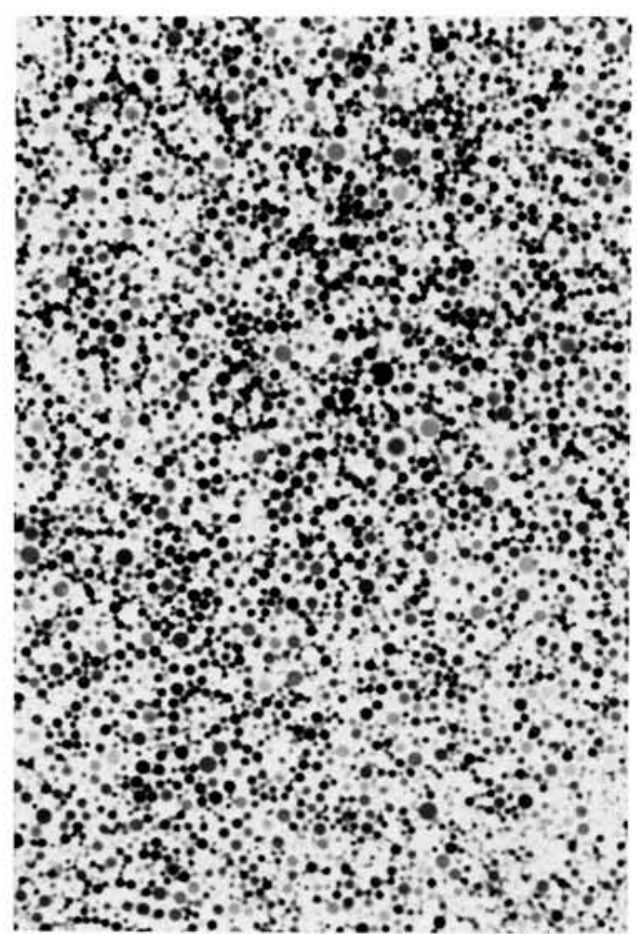

FIG 4.-Thick plastic section of granule-rich pellet after staining with toluidine blue. Although all of these granules are more dense than acinar cell granules, there is great deal of variation in size and staining qualities of these structures $(\mathrm{mag} \times 750)$.

$\mathrm{P}_{2}$ preparation showed variation in size and density of the granules (Fig 4). Each successive filtration of the $\mathrm{P}_{2}$ fraction through nuclepore filters reduced the amount of contaminating organelles as well as the final yield of the $\mathrm{wfP}_{2}$ fraction.

ELECTRON MICROSCOPY.-Centrifugation yielded a nuclear pellet that consisted of nuclei, cell membranes, aggregates of cell debris, and connective tissue which were not filtered out by the cheesecloth. The $P_{2}$ pellet after washing and filtration through the series of nuclepore filters $\left(\mathrm{wfP}_{2}\right)$ consisted mainly of secretory granules with a small amount of contaminating material (Fig 5). A similar preparation observed under the scanning electron microscope consisted of numerous rounded projections lying on top of a coated "holey" $0.8-\mu \mathrm{m}$ nuclepore filter. However, it was impossible to distinguish between small granules and mitochondria or to visualize the granule surface, 


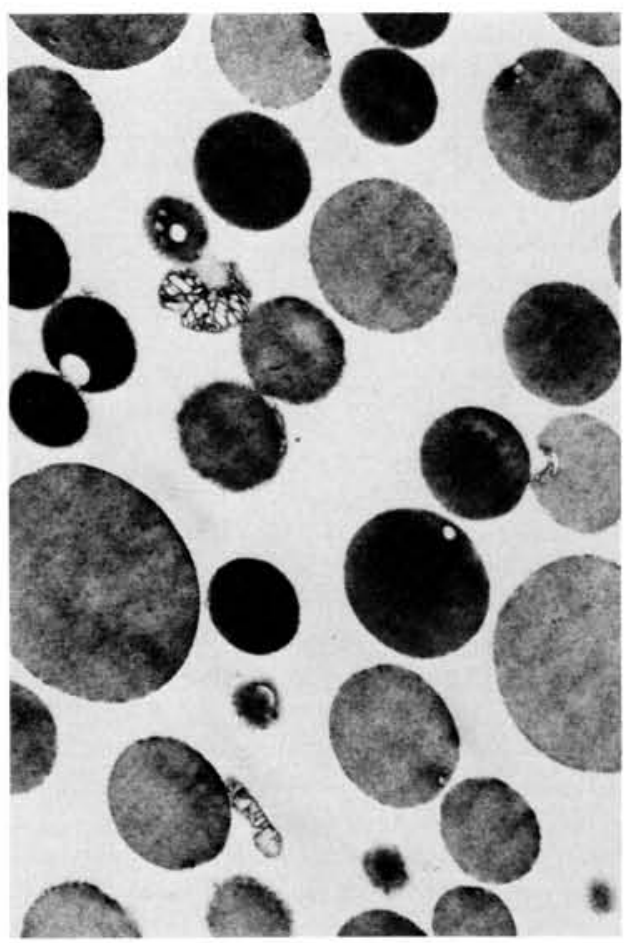

FIG 5.-Electron micrograph of granule-rich pellet shows mainly zymogen-type granules and few mitochondria. Granules exhibit homog. eneous matrices, but some are more electron dense than others $(\mathrm{mag} \times 6,500)$.

especially after coating the preparation with the gold film.

Under the transmitting electron microscope, the wfP $_{2}$ pellet consisted of a few mitochondria and many zymogen-type granules, ranging in diameter from 0.8 to 2.5 $\mu \mathrm{m}$. In different $\mathrm{P}_{2}$ preparations, there was

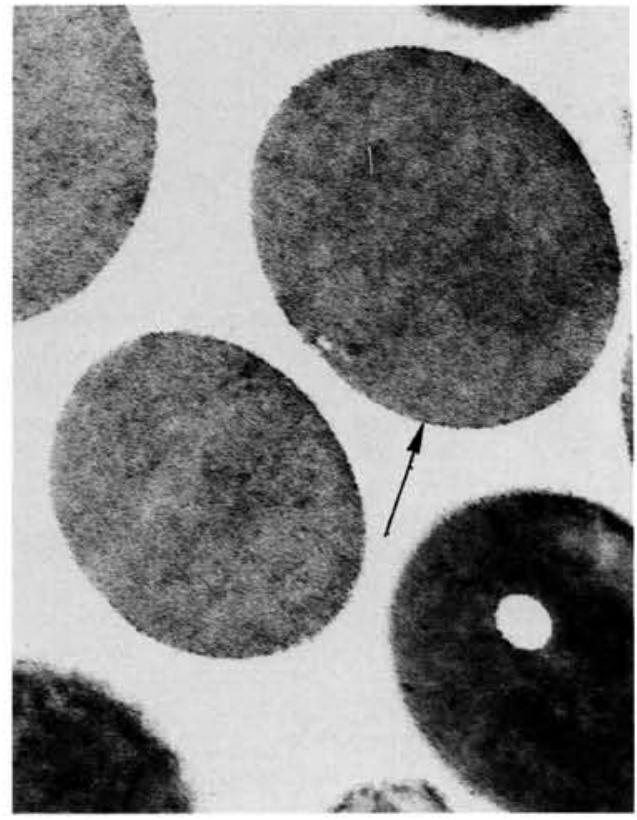

FIG 6.-Zymogen granules with homogeneous matrices are partially surrounded by unit mem. branes (arrow). No granule was observed in centrifugal fractions after homogenization which were completely surrounded by membranes (mag $\times 22,500)$.

variation in both the extent to which unit membranes surrounded individual granules as well as the density of their matrices (Fig 6). Perhaps this was due to the amount of membrane lost during homogenization and thus the degree to which soluble components could be extracted by the homogenizing medium. In all instances, however, the matrices

TABLE 1

Microscopic analysis of Organelles in Centrifugal Fractions

\begin{tabular}{|c|c|c|c|c|c|}
\hline \multirow[b]{2}{*}{ Fraction } & \multicolumn{3}{|c|}{ Particles $(\overline{\mathrm{x}} \pm S E M)$ per $150 \mu \mathrm{m}^{2}$} & \multirow{2}{*}{$\begin{array}{c}\text { Estimate }{ }^{\bullet} \text { of } \\
\text { Microsomal } \\
\text { Membrane } \\
\text { Content }\end{array}$} & \multirow{2}{*}{$\begin{array}{c}\text { Area } \\
\text { Viewed } \\
\left(\mu \mathrm{m}^{2}\right)\end{array}$} \\
\hline & $\begin{array}{c}\text { Dense } \\
\text { Granules }\end{array}$ & Mitochondria & Lysosomes & & \\
\hline$w f P_{2}$ & $\begin{array}{c}24.8 \pm 1.83 \\
(84.6 \%) \dagger\end{array}$ & $\begin{array}{l}3.7 \pm 0.86 \\
(12.6 \%)+\end{array}$ & $\begin{array}{c}0.8 \pm 0.22 \\
(2.7 \%)+\end{array}$ & - & 2,100 \\
\hline $\mathbf{P}_{3}$ & $0.5 \pm 0.85$ & $103 \pm 8.52$ & $1.0 \pm 0.85$ & ++ & 300 \\
\hline$P_{4}$ & $\ldots$ & $2.3 \pm 1.02$ & $\ldots$ & ++++1 & 450 \\
\hline
\end{tabular}

Note: SEM, standard error of the mean; wfP $_{2}$, purer granule-rich fraction; $\mathrm{P}_{3}$ mitochondria-rich fraction; $P_{4}$, microsome-rich pellet.

- - only occasional microsomal membranes; ++ , membranes of endoplasmic reticulum between mitochondria; and ++++++ , membranes of endoplasmic reticulum too dense to count.

† Percent figure represents the fraction of total particles in the area view of ffP $_{2}$. 


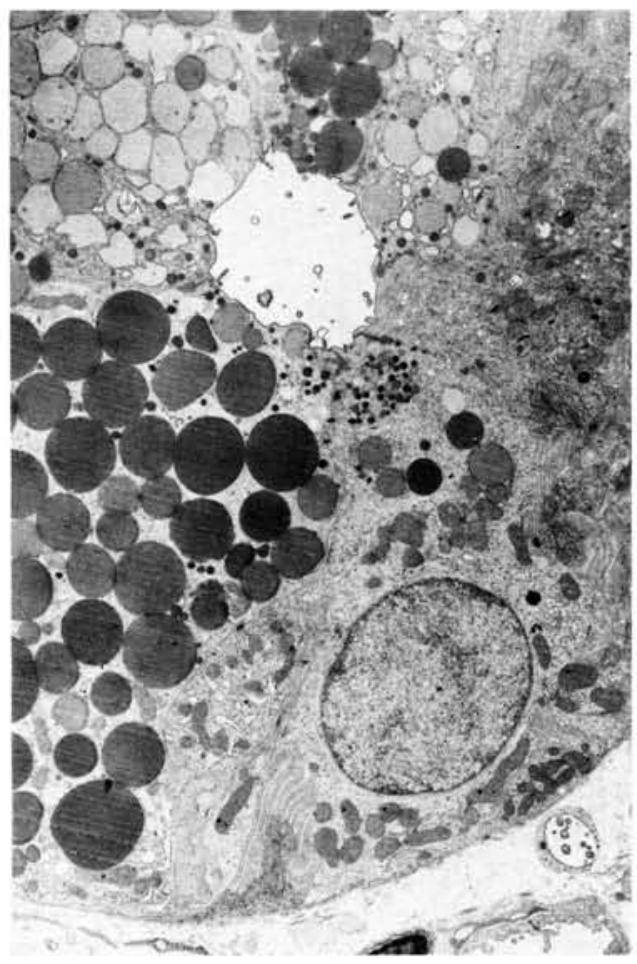

FIG 7.-Electron micrograph shows cross section of convoluted granular tubule. Granules in each cell are similar in density and size, have homogeneous matrices, are surrounded by unit membranes, and are located apical to cell nucleus $(\mathrm{mag} \times 4,000)$.

of these granules were homogeneous and dense, as in electron micrographs of whole glands (Fig 7), and could be distinguished from adjacent lysomal structures (myelin bodies and autophagic vacuoles). Because acid phosphatase histochemistry was not done on these sections, this impression could not be confirmed. In addition, acinar cell granules with paracrystalline inclusions were rarely present in the preparation. The relative numbers of different kinds of particulate structures in this preparation are shown in Table 1.

The $\mathrm{P}_{3}$ pellet (centrifuged at $11,700 \times \mathrm{g}$ for 15 minutes) consisted mainly of mitochondria but also contained a small number of granules and microsomal structures. The $\mathrm{P}_{4}$ pellet (centrifuged at $100,000 \times \mathrm{g}$ for one hour) consisted mostly of microsomes but was also contaminated with a few mitochondria and "granules."

BIochemistry.-Table 2 shows the comparative rates of hydrolysis of BAPA and BAEE at both a $\mathrm{pH}$ of 8.0 and 9.2 for centrifugal fractions from a typical experiment according to the preparation scheme. The BAPA hydrolysis rate for each fraction was the same whether the assay was done at a $\mathrm{pH}$ of 8.0 or 9.2 . The BAEE hydrolysis rates for the various fractions were slightly higher at a $\mathrm{pH}$ of 9.2 than rates at a $\mathrm{pH}$ of 8.0. In addition, the hydrolysis rate of BAPA was only 0.2 to $0.4 \%$ that of BAEE at both $\mathrm{pH}$ levels in all fractions. Proteolytic activity in other experiments was followed routinely by the hydrolysis of BAEE at a $\mathrm{pH}$ of 9.2.

Table 3 summarizes the esterase activity in the different centrifugal fractions from another experiment. In this instance, more than half $(57 \%)$ the total activity was found

TABLE 2

Comparison of RATE OF Hydrolysis* OF BAPA AND BAEE BY Fractions of RAT SMG†

\begin{tabular}{lrrrrr}
\hline \hline & \multicolumn{2}{c}{$\mathrm{pH}, 8.0$} & & \multicolumn{2}{c}{$\mathrm{pH}, 9.2$} \\
\cline { 2 - 3 } \cline { 5 - 6 } & BAPA & BAEE & & BAPA & BAEE \\
\hline Homogenate & 104.5 & 24,570 & & 110.4 & 32,100 \\
NP $(165 \times \mathrm{g}-15 \mathrm{~min})$ & 5.3 & 2,060 & & 6.4 & 1,680 \\
$\mathrm{P}_{2}(2,500 \times \mathrm{g}-15 \mathrm{~min})$ & 21.9 & 8,650 & & 21.9 & 10,350 \\
$\mathrm{P}_{3}(11,700 \times \mathrm{g}-15 \mathrm{~min})$ & 2.3 & 875 & & 2.5 & 1,050 \\
$\mathrm{P}_{4}(100,000 \times \mathrm{g}-1 \mathrm{hr})$ & 3.7 & 1,150 & & 3.8 & 1,150 \\
$\mathrm{~S}_{4}$ & 56.5 & 18,200 & & 54.5 & 18,250 \\
\% Recovery & $86 \%$ & $126 \%$ & & $86 \%$ & $101 \%$ \\
\hline
\end{tabular}

Note: NP, nuclear pellet; $P_{2}$, crude, granule-rich fraction; $P_{3}$, mitochondria-rich fraction; $P_{4}$, microsome-rich pellet; and $S_{4}$, final supernatant.

- Total activity (micromoles hydrolyzed per minute per fraction) corrected to original volume of homogenate.

+ Adult males (400 to $500 \mathrm{gm}$ each).

$\ddagger \alpha-N$-benzoyl arginine $p$-nitroanilide.

$\S \alpha$ - $N$-benzoyl arginine ethyl ester. 
TABLE 3

Distribution of Alkaline Esterase Activity in Gentrifugal Fractions

\begin{tabular}{|c|c|c|c|c|}
\hline Fraction & $\begin{array}{c}\text { Total BAEE } \\
\text { Activity* } \\
\text { ( } \mu \text { moles BA } \\
\text { Formed/ } \\
\text { fraction) }\end{array}$ & $\begin{array}{c}\% \text { of Total } \\
\text { Activity }\end{array}$ & $\begin{array}{l}\text { Total Protein } \\
\text { (mg/fraction) }\end{array}$ & $\begin{array}{l}\text { Specific Ac- } \\
\text { tivity* ( } \mu \text { moles } \\
\text { BA formed/ } \\
\text { mg protein) }\end{array}$ \\
\hline Homogenate & 42,200 & 100.0 & 466 & 90.5 \\
\hline NP & 3,660 & 8.6 & 91.5 & 40 \\
\hline $\mathbf{P}_{3}$ & 24,100 & 57 & 78.1 & 309 \\
\hline $\mathbf{P}_{\mathbf{s}}$ & 615 & 1.5 & 24.1 & 25.5 \\
\hline$P_{4}$ & 850 & 2 & $\mathbf{3 8 . 8}$ & 21.9 \\
\hline$S_{4}$ & 14,960 & 35 & 204 & 73.3 \\
\hline$\%$ Recovery & . & $104 \%$ & $93 \%$ & $\ldots$ \\
\hline
\end{tabular}

in $P_{2}$. A third of the total activity (32\%) remained after washing with homogenizing medium and filtration $\left(\mathrm{wfP}_{2}\right.$, not shown in Table 3). This suggests that a large percent of the total esterase activity was associated with organelles in the granular preparation. In addition, it is apparent that BAEE activity with a pH of 9.2 is much less in the $\mathrm{P}_{2}$ fraction than in the $\mathrm{S}_{4}$ fraction in Table 2 , and it is much more than it is in the $\mathrm{S}_{4}$ fraction in Table 3. Even with a routine homogenizing and fractionating technique, it was not uncommon for individual preparations to vary to this extent.

Table 4 shows the distribution of marker enzymes (a measure of the degree of contamination) for each fraction. That $\mathrm{wfP}_{2}$ fraction that had the highest specific esterase activity also had a small percentage of the total acid phosphatase $(4 \%)$ and total glucose-6-phosphatase $(1.4 \%)$ activities, indicating little contamination by lysosomes and microsomes, respectively. However, about $20 \%$ of the total succinoxidase activity was associated with the $\mathrm{wfP}_{2}$ fraction thus agreeing with mitochondrial contamination of this fraction.

\section{Discussion}

The histochemical activity with BANA and BAPA, when incubated at either a $\mathrm{pH}$ of 8.2 or 9.2 , was found to be distributed only over the SMG ductal system. The reaction was especially intense over the apex area of these cells, which was reminiscent of the distribution of granules within the convoluted tubules (Figs 2,3). Other substrates for these enzymes have been used but are less sensitive. For example, the granules of the convoluted tubules react positively in the p-dimethylaminobenzaldehyde reaction 23 for the tryptophane-positive sites. 24,25 In addition, fluorescein-labeled antibodies have been used to localize proteins associated with

TABLE 4

Percentages of Marker Enzyme activities in Centrifugal Fractions

\begin{tabular}{lcccc}
\hline & \multicolumn{3}{c}{ Percentages* } \\
\cline { 2 - 5 } \multicolumn{1}{c}{ Fraction } & $\begin{array}{c}\text { Alkaline } \\
\text { Esterase }\end{array}$ & $\begin{array}{c}\text { Acid } \\
\text { Phosphatase }\end{array}$ & Succinoxidase & $\begin{array}{c}\text { Glucose-6- } \\
\text { phosphatase }\end{array}$ \\
\hline Homogenate & 100 & 100 & 100 & 100 \\
NP & 8.6 & 20.6 & $\ldots .9$ &. .5 \\
$\mathbf{P}_{2}$ & 57 & 6.2 & 32.3 & 5.1 \\
wfP $_{2}$ & 32 & 4.0 & 19.8 & 1.4 \\
$\mathbf{P}_{3}$ & 1.5 & 11.1 & 36.0 & 21.2 \\
$\mathbf{P}_{4}$ & 2 & 26.0 & 18.8 & 88.5 \\
$\mathbf{S}_{4}$ & 35 & 7.8 & 65.5 & $<1.0$ \\
\hline
\end{tabular}

Note: NP, nuclear pellet; $P_{0}$, crude, granule-rich fraction; wfP $P_{g}$ purer, granule-rich fraction; $P_{3}$, mitochondria-rich fraction; $P_{4}$, microsome-rich pellet; and $S_{4}$, final supernatant.

* Total activity in fractions based on homogenate as $100 \%$. 
AEP activity to granules in the convoluted tubules of mouse SMGs. ${ }^{26}$

Since previous studies have strongly suggested that trypsinlike activity, including esteropeptidase activity in the mouse, is related to the granules of the convoluted tubules, $8,11,26$ it was expected that most of this enzymatic activity should be associated with a centrifugal fraction rich in zymogen granules. By the simplest fractionation method without any subsequent filtration or gradient manipulation, more than a half the total BAEE activity was found within the $P_{2}$ fraction in the experiment illustrated in Table 3. The total activity of this fraction $(24,000 \mu$ moles BAEE hydrolyzed/min/fraction) was $57 \%$ of the total activity of the homogenate. The final $\mathrm{S}_{4}$ fraction contained approximately a third of the total activity. A large proportion of this was probably because of breakage of the granules and solubilization of the proteins during the homogenization and isolation procedures. Since $65 \%$ of the succinoxidase activity had been found in the final $\mathrm{S}_{4}$ fraction (Table 4), mitochondria were probably also damaged during this procedure.

It was also apparent that temperature and composition of the homogenizing medium played a major role in the recovery of enzyme activity. In preliminary experiments, $0.88 M$ sucrose, $10 \mathrm{~m} M$ Tris-HCl buffer, 1 $\mathrm{m} M$ EDTA, and $1 \mathrm{~m} M$ lauryl alcohol, at a $\mathrm{pH}$ of 7.4 were used as the homogenizing medium, and all steps were done at $25 \mathrm{C}$. This was a modification of a method described by Geipert and Erdös.4 Fractionation of the gland after homogenization was easier by this method and the $P_{2}$ preparations were less contaminated with other organelles and debris. Therefore, fractionation at room temperature appeared to decrease the tendency of "stickiness" between organelles, perhaps by enhanced proteolysis. However, at the same time, the total activity of the $\mathrm{P}_{2}$ fraction was reduced to less than $1 \%$ of total activity and the specific activity was reduced to less than a quarter of the value reported in this study. More than $90 \%$ of the total esterase activity was subsequently and consistently found in the $S_{4}$ fraction, suggesting even greater disruption of granules and solubilization of proteins during the homogenization procedures. Disruption of granules and increased vacuolization of granules were confirmed by electron microscopy.

Reikkinen, Ekfors, and Hopsu ${ }^{27}$ reported a major soluble enzyme (salivain) with an optimum $\mathrm{pH}$ of 9.3 and a specific activity of $1,560 \mu$ moles $\mathrm{BAEE} / \mathrm{min} / \mathrm{mg}$ protein, isolated from whole rat SMG homogenate. In comparison, the highest specific activity reported in the present article was that of the washed and filtered $\mathrm{P}_{2}$ preparation, 327 $\mu$ moles $\mathrm{BAEE} / \mathrm{min} / \mathrm{mg}$ protein, a value which was only about a fifth of that reported by Reikkinen's group. However, their objective was to purify alkaline peptidases from homogenized glands, without regard for their association with organelles. Much of the total activity in the present experiments was lost in attempting to purify a granular fraction.

If the AEP activity is associated with granular proteins of the convoluted tubules as is suggested by these data, then most of the esterase activity at a $\mathrm{pH}$ of 9.2 represents salivary enzymes, rather than metabolic proteins associated with other organelles. This parallels the findings of Hopsu-Havu, Reikkinen, and Ekfors ${ }^{28}$ who reported that within minutes after intraperitoneal injection of isoproterenol, $0.1 \mathrm{mg} / \mathrm{kg}$, the amidase activity (BAPA) at a $\mathrm{pH}$ of 9.2 in saliva was ten times that found in the SMG homogenate. The difference in the sizes and densities of the zymogen granules (Fig 5) may result from differences in composition, that is compartmentalization of different enzymes in separate granules. However, these granules may represent two different stages of maturation, with the enzyme composition being the same in each.

\section{Conclusions}

Morphologically, the serous granules of the convoluted tubules of rat submandibular glands were satisfactorily preserved in a homogenizing medium of $0.34 M$ sucrose and 0.5 EDTA in $10 \mathrm{~m} M$ HEPES buffer at a $\mathrm{pH}$ of 7.4 and at $4 \mathrm{C}$. The preservation as well as yield of granules and total alkaline exteropeptidase activity were better than that with more concentrated sucrose in $10 \mathrm{mM}$ Tris buffer at the same $\mathrm{pH}$ at room temperature, even in the presence of the membranestabilizing agent, lauryl alcohol. Contamination of the granule-rich fraction was mainly by mitochondria. However, it is unlikely that the mitochondria are the source 
of these enzymes since such a small proportion of the total AEP activity was found in the mitochondria-rich fraction.

We are grateful for the technical assistance of Mrs. S. Johnson, Mrs. H. Carr, Ms J. Pasich, Ms P. Hollingsworth, Ms D. Riggins, Ms J. Seegert, and Mrs. H. Kassem.

\section{References}

1. BHoolA, K.D.: Comparative Study of the Subcellular Distribution of Submaxillary Kallekrein, Biochem Pharmacol 18: 1252, 1960.

2. CoHen, S.: Purification of a Nerve Growth Promoting Protein from the Mouse Salivary Gland and Its Neuro-Cytotoxic Antiserum, Proc Natl Acad Sci USA 46: 302, 1960.

3. Erdös, E.G.; TAgue, L.L.; and MrWa, I.: Kallekrein in Granules of the Submaxillary Gland, Biochem Pharmacol 17:667, 1968.

4. GeIPrRT, F., and ERDös, E.G.: Properties of Granules that Contain Kallekrein and Renin, Experientia 27: 912, 1971.

5. NAughton, M.A.; Geczy, C.; Bender, V.; HoffMan, H.; and Hamirton, E.: Esteropeptidase and Thymotropic Activity of a Protein Isolated from Mouse Submaxillary Gland, Biochim Biophys Acta 263: 106, 1972.

6. Chiang, T.S.; Erdös, E.G.; Miwa, I; Tague, L.; and CoAlson, J.J.: Isolation from a Salivary Gland of Granules Containing Renin and Kallekrein, Circ Res 23:507, 1968.

7. Pasquini, F.; Petris, A.; Sbaraglia, G.; Scopelutti, R.; Cenci, G.; and Frati, L:. Biological Activities in the Granules Isolated from the Mouse Submaxillary Gland, Exp Cell Res 86: 233, 1974.

8. SREEBNY, L.M.: Studies of Salivary Gland Proteases, Ann NY Acad Sci 85: 182, 1960.

9. Angeletti, R.A.; Angeletti, P.V.; and CalISSANO, P.: Testosterone Induction of EsteroProteolytic Activity in the Mouse Submaxillary Gland, Biochim Biophys Acta 139: 372, 1967.

10. Riekrinen, P.J., and Niemi, M.: AndrogenDependent Salivary Gland Proteases in the Rat, Endocrinology 83: 1224, 1968.

11. Shafer, W.G., and Murler, J.C.: Endocrine Influences upon the Salivary Glands, $A n n$ NY Acad Sci 85: 215, 1960.

12. SCHWert, G.W., and Takenaka, Y.: A Spectrophotometric Determination of Trypsin and Chymotrypin, Biochim Biophys Acta 16: $570,1955$.

13. Ekfors, T.O.; Malmiharju, T.; and HopsuHAvU, V.K.: Isolation of Six Trypsin-Like Esteropeptidases from the Mouse Submandibular Gland, Enzymology 43: 151, 1972.

14. Huggins, C., and Talalay, P.: Sodium Phenolphthalein Phosphate as a Substrate for Phosphatase Tests, $J$ Biol Chem 159: $399,1945$.

15. Nachlas, M.M.; Margulis, S.I.; and SeligMAN, A.M.: Site of Electron Transfer to Tetrazolium Salts in the Succinoxidase System, I Biol Chem 235: 2739, 1960.

16. Fiske, C.H., and Subbarow, Y.: The Colorimetric Determination of Phosphorus, J Biol Chem 66: 375, 1925.

17. LOWRY, O.H.; ROSEbrovGH, N.J.; FARR, A.L.; and Randall, R.J.: Protein Measurement with Folin Phenol Reagent, J Biol Chem 193: 265, 1951.

18. LUFT, J.H.: Improvements in Epoxy Resin Embedding Methods, J Biophys Biochem Cytol 9: 409, 1961.

19. Mollenhauer, H.H.: Plastic Embedding Mixtures for Use in Electron Microscopy, Stain Technol 39: 111, 1964.

20. Stempak, J.G., and Ward, R.T.: An Improved Staining Method for Electron Microscopy, J Cell Biol 22: 697, 1964.

21. REynol.ds, E.S.: The Use of Lead Citrate at High $\mathrm{pH}$ as an Electron-Opaque Stain in Electron Microscopy, J Cell Biol 17:208, 1963.

22. Hopsu, V.K., and GLenNer, G.G.: A Histochemical Enzyme Kinetic System Applied to the Trypsin-Like Amidase and Esterase Activity in Human Mast Cells, J Cell Biol 17: 503, 1963.

23. ADAMs, G.W.M.: A p-Dimethylaminobenzaldehyde-nitrite Method for Histochemical Demonstration of Tryptophane and Related Compounds, J Clin Pathol 10: 56, 1957.

24. Hanks, G.T., and Chaudhry, A.P.: Radioautographic Evidence of ${ }^{3} \mathrm{H}$-Tryptophan Incorporation in Secretory Cells of Rat Submandibular Glands, $J$ Dent Res 50: 1626, 1971.

25. Tamarin, A.; Wanamaker, B.; and Sreebny, L.M.: The Effect of Inanition of the Submandibular Salivary Glands and Exocrine Pancreas of the Rat, Ann NY Acad Sci 106: $609,1963$.

26. Ekfors, T.O., and Hopsu-HAvU, V.K.: Immuno-Fluorescent Localization of TrypsinLike Esteropeptidases in the Mouse Submandibular Gland, Histochem J 3: 415, 1971.

27. RiekKinen, P.J.; Ekfors, T.O.; and Hopsu, V.K.: Purification and Characteristics of an Alkaline Protease from Rat Submandibular Gland, Biochim Biophys Acta 118: 604, 1966.

28. Hopsu-Havu, V.K.; RIEkKinen, P.J.; and EKFORs, T.O.: Studies on the Alkaline Trypsin-Like Enzyme in Rat Submandibular Gland and Saliva, Acta Odontol Scand 25: $657,1967$. 